\title{
Can hepatic coma be caused by a reduction of brain noradrenaline or dopamine?
}

\author{
L. ZIEVE AND R. L. OLSEN
}

From the Department of Medicine, Minneapolis Veterans Hospital, University of Minnesota, Minneapolis, and Department of Chemistry, Hamline University, St. Paul, Minnesota, USA

SUMMARY Intraventricular infusions of octopamine which raised brain octopamine concentrations more than 20000 -fold resulted in reductions in brain noradrenaline and dopamine by as much as $90 \%$ without affecting the alertness or activity of normal rats. As this reduction of brain catecholamines is much greater than any reported in hepatic coma, we do not believe that values observed in experimental hepatic failure have aetiological significance for the encephalopathy that ensues.

Though catecholaminergic nerve terminals represent only a small proportion of brain synapses (Snyder $\boldsymbol{e t}$ al., 1973), the reduction in brain dopamine or noradrenaline by the accumulation of false neurotransmitters such as octopamine or of aromaticamino acids such as phenylalanine or tyrosine has been suggested as a cause of hepatic coma (Fischer and Baldessarini, 1971; Dodsworth et al., 1974; Fischer and Baldessarini, 1975; Munro et al., 1975). The following data have been cited in support of this hypothesis: a three to five-fold increase in rat brain octopamine in acute experimental hepatic coma (Fischer and Baldessarini, 1971; Fischer and James, 1971; Dodsworth et al., 1974), a five-fold increase in urinary octopamine excretion in patients with hepatic coma (Fischer and Baldessarini, 1971), a significant correlation between serum octopamine concentration and severity of hepatic encephalopathy in patients (Lam et al., 1973; Manghani et al., 1975), a reported decrease in brain noradrenaline in rats with acute experimental hepatic coma (Dodsworth et al., 1974), and a reported improvement in hepatic encephalopathy when aromatic amino acids are decreased in plasma relative to branched chain amino acids (Fischer et al., 1976). In order to test the hypothesis that reduction in brain dopamine or noradrenaline per se will cause coma, we cannulated the lateral ventricles of normal rats and infused octopamine in amounts sufficient to raise the brain octopamine more than 20000 -fold. The resulting marked reduction in the concentrations of brain

Address for reprint requests: Dr L. Zieve, VA Hospital, Minneapolis, MN 55417, USA.

Received for publication 24 February 1977 dopamine and noradrenaline had no discernible effect on the state of alertness of the animals.

\section{Methods}

\section{ANIMALS}

Male Sprague-Dawley rats weighing between 300 and $350 \mathrm{~g}$ were prepared by the method of Peterson and Sparber (1974) for intraventricular infusions of octopamine. Rats of $250-400 \mathrm{~g}$ were used as controls. All animals received regular rat chow and water ad libitum. After treatment and observation rats were killed by decapitation. Brains were removed within a few seconds and frozen immediately in liquid nitrogen. Care was taken to exclude the ventricles from the brain tissue that was analysed.

\section{CHEMICALS}

Octopamine hydrochloride, noradrenaline, and dopamine used as standards were obtained from Sigma Chemical Co. The enzyme phenylethanolamine-N-methyltransferase used in the assay for octopamine was also obtained from Sigma Chemical Co. Pargyline was obtained from Abbott Laboratories. Dihydroxybenzylamine was prepared from dimethoxybenzylamine by treatment with hydrobromic acid (Refshauge et al., 1974). S-adenosyl-Lmethionine (methyl- ${ }^{3} \mathrm{H}$ ) was obtained from New England Nuclear. Other chemicals were of usual reagent grade.

APPARATUS

For the determination of dopamine and noradrenaline a liquid chromatograph with electrochemical detection (LCEC) was assembled using a 
Milton-Roy pump (model 396-31), a $5 \mu$ l slider injection valve and a $2 \mathrm{~mm} \times 50 \mathrm{~cm}$ glass column, all from Laboratory Data Control Co., Riviera Beach, Fla. The column was packed with Dupont Zipax SCX, a strong cation exchanger. A model LC-2 electrochemical system (Bioanalytical Systems, Inc., West LaFayette, IN 47906) was used for detection.

\section{ASS A Y S}

To determine the catecholamines the rat brains were weighed frozen, homogenised with $5.0 \mathrm{ml}$ cold 0.05 $M$ perchloric acid containing $0.03 \mathrm{M}$ sodium bisulphite, and then centrifuged at $15000 \times g$ for 20 minutes. A portion of each supernate was reserved for octopamine analysis if appropriate. The remainder was used for analysis by LCEC according to the procedure of Refshauge et al. (1974), in which the supernate is treated with aluminium oxide which selectively adsorbs catecholamines. These were subsequently stripped from the alumina with acetic acid and separated chromatographically.

Octopamine was determined in frozen, weighed rat brains essentially according to the radio-enzymatic method of Saavedra (1974), the principal modification being the use of commercially prepared phenylethanolamine- $\mathrm{N}$-methyltransferase $(50 \mu \mathrm{g}$ protein in each incubation tube). In the case of rats which had not been treated to increase brain levels of octopamine the brains were homogenised in 20-30 volumes of $0.02 \mathrm{M}$ Tris buffer ( $\mathrm{pH} \mathrm{8.6)} \mathrm{containing}$ pargyline $(50 \mu \mathrm{g} / \mathrm{ml})$ as specified by Saavedra. The proteins were precipitated by heating in a boiling water bath for three minutes and centrifuging at $20000 \times g$ for 20 minutes. In the case of treated rats the supernates from the catecholamine procedure contained high levels of octopamine and were simply diluted appropriately with the $0.02 \mathrm{M}$ Tris buffer mentioned above.

\section{EXPERIMENTAL PROCEDURE}

Rats were infused intraventricularly with a $20 \mathrm{mg} / \mathrm{ml}$ solution of octopamine hydrochloride which was approximately isotonic, slightly acidic but unbuffered. In one group of six rats, the infusions were carried out four times for 20 minutes each at 90 minute intervals. The infusion rate was approximately $2 \mu \mathrm{l} / \mathrm{min}$ so that a total dose of $3.2 \mathrm{mg}$ octopamine was administered over a period of 290 minutes. Controls were either untreated or were infused on the above schedule with isotonic saline. Seventy minutes after stopping the last infusion (six hours from beginning the first infusion) the animals were killed by decapitation and brains assayed as described above. Another group of six rats was pretreated with pargyline, $10 \mathrm{mg}$ intraperitoneally, five minutes before the intraventricular infusion of octopamine. Three of the rats were infused with a total of $3.2 \mathrm{mg}$ octopamine as described above. Three additional rats were given a continuous intraventricular infusion of octopamine over a period of 20 hours. The rate of infusion was approximately 0.5 $\mu l$ per minute, and the total dose of octopamine was $12 \mathrm{mg}$.

During the infusion process, whether the material being infused was saline or the octopamine solution, the spontaneous activity of the animals decreased and some appeared lethargic. This effect was more prominent in those rats pretreated with pargyline. However, as soon as the infusion was stopped, the rats perked up promptly, appearing as alert and active as before the infusion was begun. All were alert just before decapitation. The effect of the infusion was less evident in the rats infused continuously for 20 hours, as the infusion rate--and thus intraventricular pressure-was lower.

\section{Results}

The brain octopamine concentrations in normal uninfused rats and in rats receiving intraventricular infusions of octopamine are given in the Table.

Table Brain octopamine concentrations after intraventricular infusions of octopamine*

\begin{tabular}{|c|c|c|}
\hline & No. & $\begin{array}{l}\text { Brain octopamine } \\
(\mathrm{ng} / \mathrm{g})\end{array}$ \\
\hline Control, no infusion & 6 & $3.4 \pm 0.6$ \\
\hline Control, saline infusion & 5 & $4.5 \pm 0.5$ \\
\hline \multicolumn{3}{|l|}{ Octopamine infusion } \\
\hline $3.2 \mathrm{mg}$ over $6 \mathrm{hr}$ & 6 & $115000 \pm 27000$ \\
\hline \multicolumn{3}{|l|}{ Pargyline + oct. infusion } \\
\hline $3 \cdot 2 \mathrm{mg}$ over $6 \mathrm{hr}$ & 3 & $507000 \pm 153000$ \\
\hline \multicolumn{3}{|l|}{ Pargyline + oct. infusion } \\
\hline $12 \mathrm{mg}$ over $20 \mathrm{hr}$ & 3 & $847000 \pm 63000$ \\
\hline
\end{tabular}

*Mean \pm SEM.

Infusion of saline in place of the octopamine solution had no effect on the brain octopamine concentration, nor did it alter the brain dopamine or noradrenaline concentrations. Infusions of $3.2 \mathrm{mg}$ octopamine resulted in a 20000 -fold increase in brain octopamine. Pretreatment with pargyline, a monoamine oxidase inhibitor that in itself leads to raised brain octopamine levels, resulted in a further marked increase in brain octopamine when $3.2 \mathrm{mg}$ was infused intraventricularly, and an increase to the fantastic levels of $847000 \pm 63000 \mathrm{ng} / \mathrm{g}$ when 12 mg was infused over 20 hours. In all instances the rats had recovered their preinfusion spontaneous activity and alertness before they were killed. In contrast, infusion of $0.5 \mathrm{mg}(0.01 \mathrm{mmol}) \mathrm{NH}_{4} \mathrm{Cl}$ into 
the cerebral ventricle resulted in convulsions within a few seconds and coma within a minute or two.

The brain noradrenaline (NA), and dopamine (DA) concentrations resulting from these enormous increments in brain octopamine are given in the Figure. The control values shown are based upon a combination of values obtained in four rats receiving an intraventricular saline infusion (NA $440 \pm 37$ and DA $1003 \pm 107 \mathrm{ng} / \mathrm{g}$ ) and six rats receiving no infusion (NA $364 \pm 30$ and DA $844 \pm 50 \mathrm{ng} / \mathrm{g}$ ).

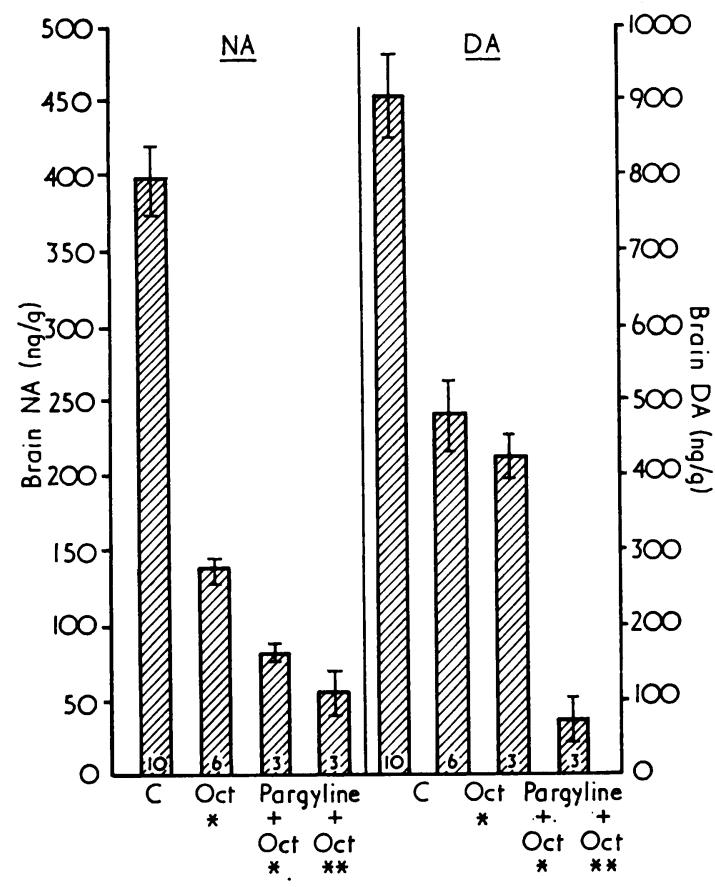

Figure Brain noradrenaline and dopamine concentrations after intraventricular infusions of octopamine. The bars give means \pm SEM. The number of rats used is indicated at the base of each bar. $N A=$ noradrenaline. $D A=$ dopamine. Oct $=$ Octopamine. $C=$ control. ${ }^{*} 3 \cdot 2 \mathrm{mg}$ over $6 \mathrm{hr} .{ }^{* *} 12 \mathrm{mg}$ over $20 \mathrm{hr}$.

After intraventricular infusion of $3 \cdot 2 \mathrm{mg}$ octopamine alone the average brain NA was reduced to $34 \%$ of the control. Infusion of $\mathbf{3 . 2} \mathrm{mg}$ and $\mathbf{1 2} \mathrm{mg}$ after pretreatment with pargyline resulted in further reduction to $21 \%$ and $14 \%$ of the control. In the presence or absence of pargyline, intraventricular infusion of 3.2 $\mathrm{mg}$ resulted in an average reduction in brain DA of approximately $50 \%$. With the infusion of $12 \mathrm{mg}$ after pretreatment with pargyline the average brain DA was reduced to $8 \%$ of control. Thus extreme reductions in the brain content of NA and DA were not associated with loss of consciousness in any of these rats.

Acute experimental hepatic coma was produced in six rats by ligation of the hepatic artery 18-24 hours after a portacaval shunt as described previously (Zieve et al., 1974). The rats lapsed into coma nine to 17 hours after acute massive hepatic necrosis resulting from the artery ligation and were killed as soon as coma became definite as judged by their failure to roll over when placed on their backs and their lack of response to a painful stimulus. Their average brain NA was $358 \pm 9 \mathrm{ng} / \mathrm{g}$ and DA $979 \pm 79 \mathrm{ng} / \mathrm{g}$, within the range of controls.

\section{Discussion}

It is clearly apparent from these studies that brain noradrenaline and dopamine can be reduced acutely without altering the state of consciousness of the animals. Loss of approximately $90 \%$ of these brain catecholamines did not result in coma. In our small sample of six rats in acute experimental hepatic coma, we observed normal brain concentrations of noradrenaline and dopamine. In the sample of rats reported by Dodsworth et al. (1974) to be in hepatic coma after a similar procedure the brain noradrenaline was reduced by one-third if the animals were not moribund, and by one-half if they were moribund. Thus, at the very worst, in this experimental model of acute hepatic coma the brain noradrenaline is reduced by only $50 \%$. Yet we have shown that acute depletion of noradrenaline and dopamine of much greater degree was not associated with coma. While changes in brain catecholamines may occur in hepatic failure as false neurotransmitters or aromatic amino acids accumulate, we do not believe that these abnormalities can account for the presence of hepatic encephalopathy in view of the observations reported here.

What then is the significance of the relationship observed clinically between the accumulation of octopamine and hepatic encephalopathy? This is probably another example where correlation does not signify causation. The aromatic amines are produced in the gut by bacterial action along with ammonia and mercaptans, substances known to cause coma experimentally. As with these other substances, the amines are normally efficiently removed by the liver. In the presence of portal-systemic shunting and impaired liver function these substances accumulate in the blood, brain, and other tissues. One can understand why ammonia and mercaptan accumulation in the brain, and to some extent in the blood, should correlate with the presence of encephalopathy, because it has been demonstrated that these substances induce coma. Any substance that follows 
the same route that they do into the circulation and that enters tissues more or less similarly would be expected to change more or less as they do. One would not expect perfect correlations between blood levels of any pair of these substances or between severity of encephalopathy and the observed blood levels, because variable tissue (particularly muscle) uptake would alter blood concentrations variably. However, significantly positive correlations such as reported by Manghani et al. (1975) and Lam et al. (1973) should not come as a surprise. If the build-up of amines such as octopamine in the clinical situation were, in fact, a circumstance leading to hepatic coma, as has been hypothesised, then coma should occur when a greatly increased concentration of octopamine in the brain is produced artificially as in the experiments of this report. This was not the case.

We are indebted to Dr Sheldon Sparber for showing us how to cannulate the cerebral ventricle of the rat.

\section{References}

Dodsworth, J. M., James, J. H., Cummings, M. C., and Fischer, J. E. (1974). Depletion of brain norepinephrine in acute hepatic coma. Surgery, 75, 811-820.

Fischer, J. E., and Baldessarini, R. J. (1971). False neurotransmitters and hepatic failure. Lancet, 2, 75-80.

Fischer, J. E., and Baldessarini, R. J. (1975). Neurotransmitter metabolism in hepatic encephalopathy (Letter.) $\mathrm{New}$ England Journal of Medicine, 293, 1152-1153.
Fischer, J. E., and James, J. H. (1971). Mechanism of action of L-dopa in hepatic coma. Surgical Forum, 22, 347-349.

Fischer, J. E., Rosen, H. M., Ebeid, A. M., James, J. H., Keane, J. M., and Soeters, P. B. (1976). The effect of normalization of plasma amino acids on hepatic encephalopathy in man. Surgery, 80, 77-91.

Lam, K. C., Tall, A. R., Goldstein, G. B., and Mistilis, S. P. (1973). Role of a false neurotransmitter, octopamine, in the pathogenesis of hepatic and renal encephalopathy. Scandinavian Journal of Gastroenterology, 8, 465-472.

Manghani, K. K., Lunzer, M. R., Billing, B. H., and Sherlock, S. (1975). Urinary and serum octopamine in patients with portal-systemic encephalopathy. Lancet, 2, 943-946.

Munro, H. N., Fernstrom, J. D., and Wurtman, R. J. (1975). Insulin, plasma amino acid imbalance, and hepatic coma. Lancet, 1, 722-724.

Peterson, D. W., and Sparber, S. B. (1974). Increased fixedratio performance and differential $d$ - and 1-amphetamine action following norepinephrine depletion by intraventricular 6-hydroxydopamine. Journal of Pharmacology and Experimental Therapeutics, 191, 349-357.

Refshauge, C., Kissinger, P. T., Dreiling, R., Bland, L., Freeman, R., and Adams, R. N. (1974). New high performance liquid chromatographic analysis of brain catecholamines. Life Sciences, 14, 311-322.

Saavedra, J. M. (1974). Enzymatic-isotopic method for octopamine at the picogram level. Analytical Biochemistry, 59, 628-633.

Snyder, S. H., Young, A. B., Bennett, J.P., and Mulder, A.H. (1973). Synaptic biochemistry of amino acids. Federation Proceedings, 32, 2039-2047.

Zieve, F. J., Zieve, L., Doizaki, W. M., and Gilsdorf, R. B. (1974). Synergism between ammonia and fatty acids in the production of coma: implications for hepatic coma. Journal of Pharmacology and Experimental Therapeutics, 191, 10-16. 